\title{
Rural and Urban Attitudes toward Immigrants in the U.S. Midwest and Great Plains
}

\author{
${ }^{1}$ Miguel Ceballos, ${ }^{2}$ Oksana Yakushko and ${ }^{3}$ Courtney Lyons \\ ${ }^{I}$ West Chester University of Pennsylvania, West Chester, Pennsylvania, United States \\ ${ }^{2}$ Pacifica Graduate Institute, Carpinteria, California, United States \\ ${ }^{3}$ State Legislature of Nebraska, Lincoln, Nebraska, United States
}

Article history

Received: 27-09-2014

Revised: 07-10-2014

Accepted: 31-12-2014

Corresponding Author: Miguel Ceballos,

West Chester University of Pennsylvania, West Chester, Pennsylvania, United States Email: mceballos@wcupa.edu

\begin{abstract}
Recent immigration has transformed much of the Midwest and Great Plains regions of the United States, affecting its rural and urban areas through dramatic increases in the foreign-born population and in particular Latino immigrant populations. This study examines three theories of prejudice: Perceptions of threat, contact with immigrants and a cosmopolitanism outlook, in predicting rural and urban attitudes toward immigrants in Nebraska, a state experiencing a substantial rise in immigrant populations. We use a large, randomly drawn sample of individuals across the state of Nebraska. Using ordinary least squares methods we show that the effects of perceived threat, contact and a cosmopolitan outlook vary within and between rural and urban areas of the state. Perceived threat was found to have the greatest negative effects on attitudes toward immigrants for those who live in small cities and the open country or on farms, while contact with immigrants and a cosmopolitan outlook was found to have the greatest positive effect on attitudes for those living in large cities and for towns. Implications for growing the Latino population are discussed.
\end{abstract}

Keywords: Attitudes, Immigrants, Prejudice, Rural, Urban

\section{Introduction}

Recent immigration has transformed much of the Midwest and Great Plains regions of the United States, affecting its rural and urban areas through dramatic increases in the foreign-born population (USCB, 2005). Many communities in these regions have undergone a demographic transformation due to a significant influx of immigrants and refugees over a relatively short period of time (Gouveia et al., 2005; USCB, 2005). With the rise in the number of immigrants to nontraditional destination states, the potential for a risen hostility, resentment and feelings of competition toward immigrants has increased. In addition, a significant proportion of this immigration to rural areas is due to economic growth and transformation of the regions. In this study we build on this research by examining the heterogeneity of attitudes toward immigrants within and between rural and urban areas. We focus on the experience of immigration to the state of Nebraska in order to more closely understand the characteristics and correlates of these attitudes related to the increased immigration in the Midwest and Great Plains regions of the United States.
First, we examine whether there is variation in attitudes toward immigrants within and between the rural and urban areas in the state. Then we analyze these differences within the context of the theories of threat, contact and cosmopolitanism to determine if they influence attitudes toward immigrants differently by region.

\section{Attitudes toward Immigrants in Nebraska}

Current census data show that although Nebraska and other Great Plains and Midwestern states do not have the same large numbers of recent immigrants and refugees as historically immigrant-receiving states, such as California, New York and Texas (USCB, 2005). Nebraska has experienced a tremendous growth and transformation of the immigrant population in recent decades, relative to the rest of the country's growth of the immigrant population. Indeed, the increase in the number of immigrants of the last three decades stands in opposition to relatively low growth of this population during the prior 70 years (Gouveia et al., 2005; USCB, 2005). Small urban and rural communities in Nebraska have experienced increases in the number of immigrants, mainly because the state's economy is closely tied to 
immigration: The state's agricultural and meatpacking industries employ a large immigrant workforce, immigrants generate significant entrepreneurial activities through small businesses and immigrants are employed in production, service and management/professional fields throughout the state (Gouveia et al., 2005). From 1990 to 2010, the Latino population in Nebraska increased $350 \%$ and significantly more in non-urban areas (Ennis et al., 2011; Guzmán, 2001). In rural west Nebraska, for example, the Latino population of the city of Lexington, where a large meatpacking plants is located, grew from approximately $6 \%$ of the population in 1990 to $60 \%$ in 2014 (Bodvarsson and Van den Berg, 2003; USCB, 2014). In addition, refugees and immigrants from Asia and Africa constitute $30 \%$ of the Nebraska's foreign-born population (OLLAS, 2010).

Native-born Nebraskans have not remained neutral in their reactions to the demographic transformations within their communities. More than eighty-five percent of Nebraskans in non-urban areas hold a negative view of Latino immigrants (Vogt et al., 2006). Federal raids to identify and deport undocumented immigrant workers employed at meat-packing plants contributed to a "backlash" against immigrants in these communities and across the state (Capps et al., 2007). Residents of the City of Fremont, Nebraska in recent years have passed referendums prohibiting the hiring of and renting to undocumented immigrants (Fitzsimmons, 2014; Hovey, 2010). The city's state representative during the 2011 legislative session announced plans to introduce legislation requiring local law enforcement to impose national immigration laws in the state (Jenkins 2010). These growing negative attitudes toward immigrants and immigration can cause disharmony within communities, further illustrating the importance of studying how and why they form.

\section{Theories of Attitudes toward Immigrants}

Most theories explaining attitudes toward immigrants have highlighted the contribution of the perceived threat of immigrants to the increase in hostile attitudes toward newcomers (Yakushko, 2009). Explanations for these feelings of threat include challenges to the economic well-being of the in-group and competition over jobs, although studies have not consistently found support for this hypothesis (Hainmueller and Hiscox, 2007; Mayda, 2006; Ochoa, 2000; Quillian, 1995; Sorensen and Krahn, 1996; Thornton and Mizuno, 1999; Yakushko, 2009). Other theories hypothesize perceptions of threat derive from competition over access to limited resources and public services, such as education, medical and social services (Sherif et al., 1961) personal safety (Mayda, 2006) and conflicting world views, values, beliefs and attitudes (Stephan and Stephan, 1996; Stephan et al., 1999).
Among those theories highlighting factors that increase favorable attitudes toward immigrants, contact theory has received the most attention. Contact theory (Allport, 1954) posits that prejudice toward minority groups result from the lack of contact between individuals from majority and minority backgrounds. Allport (1954) theorized that the inability to see similarities between oneself and the perceived "other" results in the creation of stereotypes and intolerance. Studies have found that interactions, close relationships and self-identification with immigrants may contribute to the reduction of negative attitudes toward immigrants (Esses et al., 2001; Federico and Fennelly, 2008; Gimpel and Lay, 2008; Hovey et al., 2000; McLaren 2003; Ward and Masgoret 2006).

A more recent theory on attitudes toward immigrants is the concept of cosmopolitanism, or a global world view. This perspective originated from the concept of the New Class and studies of Australian immigration (Bean, 1995; Betts, 1988; Bruce-Briggs, 1979). It posits that liberals and the highly educated upper and middle-class professionals acquire a global worldview through socialization and the acquisition of social status and prestige and as a consequence, favor more open immigration policies. Studies have found that education and work skill, (Hainmueller and Hiscox, 2007; Hovey et al., 2000; Mayda, 2006), a global outlook on the world (Berg, 2009; Haubert and Fussell, 2006), egalitarian and humanitarian views (Pantoja, 2006) and cross-cultural exposure (Alvarado, 2009; Scheunpflug, 1997; Haubert and Fussell, 2006) contribute to more positive attitudes toward immigrants. In contrast, those with less formal education and exposure to global ideas are more likely to hold antiimmigrant views (Hovey et al., 2000).

Lastly, various demographic factors have been found to be associated with attitudes toward immigrants. Women, younger individuals and racial and ethnic minorities have been shown to have a more positive view of immigrants and immigration than men, older individuals and whites (Boehnke et al., 1998; Leong and Ward, 2006; Streeck-Fischer, 1999). Income and education are positively associated with attitudes toward immigrants (Haubert and Fussell, 2006) and those living in rural areas or in the US South are more likely to have anti-immigration views than residents of urban areas or of regions outside of the South (Federico and Fennelly, 2008).

In a previous study of the state of Nebraska, the authors (Ceballos and Yakushko, 2014) found perceived threat to be associated with unfavorable attitudes toward immigrants while contact with immigrants and a cosmopolitan outlook were associated with favorable attitudes toward immigrants. We extend this research by investigating rural and urban differences in attitudes towards immigrants in Nebraska. We specifically seek to 
test the current theoretical suppositions that are hypothesized to intensify and lessen prejudice toward immigrants as they apply to differences in attitudes toward immigrants between and within rural and urban areas.

\section{Rural and Urban Attitudes toward Immigrants}

Theories of threat and demographic predictors have been examined in urban and rural contexts. Scholars have suggested that individuals in rural communities tend to hold more negative views of immigrants and immigration. Federico and Fennelly (2008) found that rural residents in Midwestern states hold mostly negative and restrictionist views of immigration. One explanation is that the attitudes reflect the demographic composition of the region. For example, rural populations tend to be older, have lower incomes and lower levels of education than urban populations (Chandler and Tsai, 2001; Citrin and Sides, 2007; Scheve and Slaughter, 2001). In addition, the economic challenges in rural areas coupled with the perception that immigrants are contributing to decreases in access to jobs and resources further contribute to higher negative views toward immigrants as compared to those living in urban areas (ERS, 2004; Jones and Larson, 2003). However, the link between the socio-economic status, especially income and prejudice toward immigrants among individuals from rural areas has been challenged. Neal and Bohon (2003) found that in a large community poll conducted in the state of Georgia, income was not significantly predictive of attitudes toward immigrants. Similarly, in a study of attitudes toward immigrants displayed by rural adolescents, Gimpel and Lay (2008) found that contrary to previous research, "lower income youth are more welcoming of immigration than the affluent, particularly when they live near them" (p. 180).

Education, a variable related to income status, has also been identified as a contributor to more positive views of immigrants. Because individuals from rural areas are more likely to have attained less formal education than their urban counterparts, they are also more likely to hold anti-immigrant views (Hainmueller and Hiscox, 2007; Hovey et al., 2000). However, similar to income, education has not been consistently found to be predictive of attitudes toward immigrants (Neal and Bohon, 2003).

Another factor suggested to contribute to differences in xenophobic attitudes between urban and rural-based individuals is related to differences in direct contact these individuals may have with recent immigrants. According to Federico and Fennelly (2008) many scholars speculate that rural residents' attitudes toward immigrants are also due to greater isolation and lesser contact with immigrants and minorities. These assumptions are related to the contact theory of prejudice, which posits that prejudice toward minority groups is directly related to the amount of contact between individuals from majority and minority backgrounds. These theoretical assumptions have been supported through past research. Esses et al. (2001) found that helping individuals acknowledge their own immigrant roots resulted in improved attitudes toward recent immigrants. Similarly, a study by Hovey et al. (2000) showed that those individuals who are unable to identify with immigrants and immigration in their family experiences were found to hold stronger xenophobic views.

Although studies have looked at rural or urban attitudes toward immigrants, few, if any, have looked at variation within rural and urban areas. Rural is a broad category which includes differences in region (ranging in distance from urban centers), boundaries (administrative, land-use and economic production) and population size (from tens to hundreds of thousands). Urban also includes large and small metropolitan areas, as well as suburbs and exurbs (Cromartie and Bucholtz, 2008).

A more thorough study of variation of attitudes within rural and urban areas can add to this existing literature. Specifically, although theoretical and empirical knowledge exists about differences in attitudes toward immigrants between individuals from rural and urban backgrounds, many studies are inconsistent and many assumptions remain untested. For example, rural areas are often assumed to be homogeneous and defined only in reference to urban. Thus, what is not urban is simply defined as rural. However, there are various definitions of rural that can range from populations less than 2,500 to as high as 50,000 (Cromartie and Bucholtz, 2008). Rural areas may consist of small cities, towns, villages, farms and sparsely populated regions such as "open country." Likewise, urban areas are also assumed to be homogeneous, but these regions not only vary in definition, including large metropolitan urbanized centers and suburbs, but also overlap with that of the rural area definition, as in the case of small cities or towns (Cromartie and Bucholtz, 2008).

An important question is whether attitudes toward immigrants differ within these different regions. Are small cities and towns larger than 2,500 more like metropolitan urban centers or more like rural areas? Are rural towns and villages with populations less than 2,500 more similar to small cities and larger towns, or to farms or open country? In this study, our data on attitudes in Nebraska may provide us with a better description of differences within these rural areas, since Nebraska has one of the largest rural populations in the country (in proportion to its total population) and a significant proportion of the population (40\%) lives outside and away from the metropolitan urban centers 
of the state (USCB, 2005). Therefore, the research questions guiding our study are: What factors influence rural attitudes in the Great Plains region toward immigrants, how do these differ from the attitudes among the urban population and is there variation in these attitudes within rural and urban areas? Using the theories of threat, contact and cosmopolitanism, we look to address these pertinent questions.

\section{Materials and Methods}

\section{The Data}

We derived data for this analysis from the 2006 Nebraska Annual Social Indicators Survey (NASIS), conducted by the Bureau of Sociological Research at the University of Nebraska-Lincoln. NASIS is a random sample telephone survey, conducted annually, drawn from a population of adult, non-institutionalized persons living in households in the state of Nebraska (BSR, 2006a). Our sample consisted of 1,821 completed interviews, with an overall response rate of $33 \%$. The data were weighted according to selected geographic household and individual characteristics by U.S. Census distribution to assure representativeness. The data were found to be representative of the state of Nebraska's population (BSR, 2006b). Specific to our study, the 2006 survey included a broad range of questions related to perceptions of and attitudes toward immigrants, the respondents' relationship and interactions with immigrants and the perceived effect of immigrants on the social, cultural and economic well-being of society. The NASIS survey also included information collected on various social and demographic characteristics of the respondents and their geographical areas of residence.

For this analysis we use a dependent variable that is a composite measure of attitudes toward immigrants constructed from eight variables: Four representing favorable attitudes toward immigrants and four representing unfavorable attitudes. The four variables representing favorable attitudes include a five item response (from very likely to very unlikely and from strongly agree to strongly disagree) on topics of whether immigration contributes to new ideas and cultures, diversity in the community and economic growth, and whether it improves the community's economy. The four variables representing unfavorable attitudes also include a five item response (from very likely to very unlikely and from strongly agree to strongly disagree) on topics of whether immigration contributes to an increase in the crime rate, higher job loss, and government spending and whether the number of immigrants coming to their community should be decreased.
A composite standardized scale was constructed from these eight five-item variables that range from -1.51 to 1.78, with positive values representing favorable attitudes toward immigrants and negative values representing unfavorable attitudes (Table 1). The scale is highly reliable with a Cronbach alpha coefficient of 0.82 . The mean 0.06 for this scale indicates a slightly positive attitude overall.

Although a significant portion of Nebraska is rural, the majority of the population (55\%) lives in the eight urban counties of the state (USCB, 2013). We construct a rural-urban variable that places each respondent according to residence into one of four regional categories: Those living in open country or on a farm $(14 \%)$, in a town $(23 \%)$, in a small city or metropolitan a suburb or exurb (19\%) and in the cities of Lincoln or Omaha (44\%).

In this study we assessed the differential effects of perceived threat, contact and a cosmopolitan outlook on attitudes toward immigrants in these four rural-urban categories. We summarize the independent variables representing these hypotheses here. To test the threat hypothesis we use five variables: Immigrant visibility ("how often are immigrants seen in the community": Very often or often $=1$, otherwise $=0$ ), perceived increase in immigration("compared to 10 years ago do you think there are more, the same, or less immigrants in your community now?": More now $=1$, otherwise $=$ 0 ), community safety (whether respondents feel less safe from crime in their community over the past two years: Not safe $=1$, safe $=0$ ), employment (if the respondent or spouse is employed: Either is employed $=1$, otherwise $=0$ ) and the percentage of Latinos living in the counties, based on census data. At the time of the survey about $6 \%$ of the state's population was Latino (USCB, 2005). We used $6 \%$ as a cutoff to create a variable for respondents living in those counties with a Latino population greater than $6 \%$ (a county with greater than $6 \%$ Latino $=1$, otherwise $=0$ ). While these variables are not direct measures of threat associated with immigration, they may influence the individual's general perceptions of immigrants threatening their personal and economic security.

Table 1 displays the results: $63 \%$ of the respondents reported seeing immigrants often, $82 \%$ believe that immigration has increased over the past 10 years and $42 \%$ of respondents live in counties with over $6 \%$ Latinos. One-quarter of the respondents felt they lived in a community that was unsafe and $86 \%$ report themselves or their spouses as being employed.

The contact hypothesis is tested using two variables: The frequency of interaction with immigrants: "How often do you interact with immigrants in the 
community?" (very often to sometimes $=1$, rarely or never $=0$ ) and type of interaction with immigrants: Whether or not the respondent has friends, relatives, or close acquaintances who are recent immigrants (does have $=1$, does not have $=0$ ). Sixty-five percent of the respondents reported frequent interaction with immigrants in the community and $23 \%$ reported having a friend, relative, or close relationship which someone who was a recent immigrant.

The cosmopolitan outlook measure was tested using three variables based on the conceptualization by Bean (1995; Betts, 1988) and operationalization from various studies (Chandler and Tsai, 2001; Espenshade and Hempstead, 1996; Haubert and Fussell, 2006), including: Traveled abroad (traveled abroad $=1$, not traveled abroad), liberal values (liberal $=1$, conservative $=0$ ) and a college education (B.A. or higher $=1$, less than B.A. = 0). A significant percentage of the respondents reported having traveled outside of the United States (64\%), 18\% self-identify as liberal and $36 \%$ report having at least a B.A. degree.

Gender and age are two covariates commonly found to be associated with attitudes toward immigrants. Gender is a dichotomous variable (male $=1$, female $=0$ ) and age is a continuous variable (number of years). In the NASIS data $50 \%$ of the sample is male and the average age is 46.3 years.
Although racial, ethnic and cultural differences between the immigrant and majority population has also been hypothesized to influence attitudes of native-born residents (Espenshade and Hempstead, 1996; Hood and Morris, 1998; Mayda, 2006; Wilson, 2001), because there is little racial variation in the rural areas of the state, race is not included in this analysis.

After listwise deletion the sample for analysis was reduced to 1566 . The distribution of missing cases across the variables as indicated from Table 1 suggests that missing data in the final analysis is likely completely random.

Table 2 displays the distribution of attitudes scale by the rural and urban categories. A Fisher-Hayter pairwise comparison test shows that those living in the large cities have significantly more positive attitudes $(p<0.001)$ than in those open country or on farms, whereas there is no significant difference between the regions outside of the large cities.

Using ordinary least squares regression analysis we first assess the mediating effect of living in a rural and urban area on the relationship between attitudes toward immigrants and threat, contact and a cosmopolitan outlook. We then evaluate the effects of the theoretical suppositions within the rural and urban areas. The composite attitudes scale is used as the dependent variable in each of the following analyses.

Table 1. Descriptive statistics of independent variables

\begin{tabular}{|c|c|c|c|c|c|}
\hline Variable & Obs. & Mean & S.D. & Min & Max \\
\hline Attitudes scale & 1814 & 0.06 & 0.66 & -1.51 & 1.78 \\
\hline Immigrant visibility & 1795 & 0.61 & & 0.00 & 1.00 \\
\hline Perceived increase & 1771 & 0.82 & & 0.00 & 1.00 \\
\hline Latino population ( $>6 \%$ in county) & 1821 & 0.41 & & 0.00 & 1.00 \\
\hline Community safety (unsafe $=1$ ) & 1773 & 0.26 & & 0.00 & 1.00 \\
\hline Employment & 1821 & 0.84 & & 0.00 & 1.00 \\
\hline Interaction & 1802 & 0.64 & & 0.00 & 1.00 \\
\hline Close relationships & 1810 & 0.23 & & 0.00 & 1.00 \\
\hline Traveled abroad & 1821 & 0.64 & & 0.00 & 1.00 \\
\hline Liberal & 1726 & 0.18 & & 0.00 & 1.00 \\
\hline Education $($ B.A. or higher $=1$ ) & 1744 & 0.36 & & 0.00 & 1.00 \\
\hline Gender $($ male $=1)$ & 1820 & 0.52 & & 0.00 & 1.00 \\
\hline Age & 1810 & 46.42 & 17.41 & 19.00 & 99.00 \\
\hline \multicolumn{6}{|l|}{ Rural-urban:* } \\
\hline Open country, farm & 213 & 0.14 & & 0.00 & 1.00 \\
\hline Town & 357 & 0.23 & & 0.00 & 1.00 \\
\hline Small city, suburb, exurb & 300 & 0.19 & & 0.00 & 1.00 \\
\hline Large city & 696 & 0.44 & & 0.00 & 1.00 \\
\hline
\end{tabular}

Note: Sample is weighted; *Missing cases not included

Table 2. Descriptive statistics of attitudes scale by rural and urban category in Nebraska

\begin{tabular}{llllll}
\hline Variable & Obs. & Mean & S.D. & Min & Max \\
\hline Open country, farm & 213 & -0.15 & 0.62 & -1.51 & 1.53 \\
Town & 357 & -0.03 & 0.64 & -1.51 & 1.67 \\
Small city, suburb, exurb & 300 & -0.05 & 0.64 & -1.51 & 1.64 \\
Large city & 696 & $0.19^{* * *}$ & 0.65 & -1.51 & 1.78 \\
\hline
\end{tabular}

*** Significantly different from other three regions, $\mathrm{p}<0.001$ 


\section{Results}

Table 3 displays the results for the variables representing different hypotheses. The coefficients representing place of residence show that those living in urban areas (coef. $=0.25 ; \mathrm{p}<0.001$ ) and in towns (coef $=$ $013 ; \mathrm{p}<0.05$ ) have significantly more positive attitudes toward immigrants than those living in open country or on farms (the omitted category). Attitudes of Nebraskans living in small cities or suburbs (coef $=0.11 ; \mathrm{p}<0.10)$ are also significant more positive from those living in open country or farms, however only marginally.

The variable representing the threat hypotheses indicate that seeing immigrants often (coef $=-0.20$; $\mathrm{p}<0.001$ ), perceiving an increase in the number of immigrants (coef $=-0.15 ; \mathrm{p}<0.001)$ and feeling less safe in one's community (coef $=-0.16 ; p<0.001)$ are all associated with more unfavorable attitudes toward immigrants. The proportion of Latinos living in a county and being employed are not significantly related to attitudes toward immigrants. These results are consistent with the threat hypothesis: The perceptions of threat contribute to more negative attitudes toward immigrants.

The variables measuring interaction $($ coef $=0.19$; $\mathrm{p}<0.001$ ) and close relationships with immigrants (coef $=$ $0.23 ; \mathrm{p}<0.001$ ), have a significantly positive effect on attitudes, consistent with the contact hypothesis, suggesting that an increase in contact contributes to more positive attitudes toward immigrants. The cosmopolitan outlook variables show that a liberal perspective (coef $=0.21 ; \mathrm{p}<0.001)$ and having a college degree $($ coef $=0.29 ; \mathrm{p}<0.001)$ are statistically significant in contributing to more positive attitudes, while traveling abroad in not significantly related attitudes toward immigrants. This finding is consistent with the hypothesis that a more cosmopolitan outlook is associated with more positive attitudes toward immigrants. Finally, gender is not significantly associated with attitudes toward immigrants and but those who are older are more likely ( $\operatorname{coef}=-0.01$; $\mathrm{p}<0.001)$ to have negative attitudes toward immigrants.

Next, we compare the effects of each theoretical supposition on attitudes toward immigrants. We analyze the full model for each of the four rural-urban categories. Table 4 displays the unstandardized and standardized regression coefficients for each model. The results show that except for those living in open country or on farms, in each of the rural-urban areas, perceived threat, contact with immigrants and a cosmopolitan outlook do explain attitudes toward immigrants in the expected direction. However, there are some important differences between groups. In the case of the threat variables, the perception that the number of immigrants has increased is not

significant for those living in small cities or suburbs and only marginally significant for those living in large cities, and community safety is not significant for towns. For the contact variables, close relationships with immigrants is not significant for small cities or suburbs. For the cosmopolitan outlook variables, interestingly, travelling abroad is only significantly associated with attitudes toward immigrants for those living in towns. However, having a liberal perspective is only significantly associated with attitudes for those living in large cities. Finally, for small cities or suburbs, age is not statistically significant.

Table 3. Linear regression models of attitudes toward immigrants in Nebraska

\begin{tabular}{|c|c|}
\hline Variable & Coefficients \\
\hline \multicolumn{2}{|c|}{ Rural-urban (open country, farm omitted) } \\
\hline Town & $\begin{array}{l}0.13^{*} \\
(0.06)\end{array}$ \\
\hline Small city, suburb, exurb & $\begin{array}{l}0.11 \dagger \\
(0.06)\end{array}$ \\
\hline Large city & $\begin{array}{l}0.25^{* * *} \\
(0.06)\end{array}$ \\
\hline \multicolumn{2}{|l|}{ Threat } \\
\hline Immigrant visibility & $\begin{array}{l}-0.20 * * * \\
(0.04)\end{array}$ \\
\hline Perceived increase & $\begin{array}{l}-0.15^{* * *} \\
(0.05)\end{array}$ \\
\hline Proportion Latino & $\begin{array}{l}-0.02 \\
(0.04)\end{array}$ \\
\hline Community safety (unsafe $=1$ ) & $\begin{array}{l}-0.16^{* * *} \\
(0.04)\end{array}$ \\
\hline Employment & $\begin{array}{l}-0.01 \\
(0.05)\end{array}$ \\
\hline \multicolumn{2}{|l|}{ Contact } \\
\hline Interaction & $\begin{array}{l}0.19 * * * \\
(0.04)\end{array}$ \\
\hline Close relationships & $\begin{array}{l}0.23 * * * \\
(0.05)\end{array}$ \\
\hline \multicolumn{2}{|l|}{ Cosmopolitan outlook } \\
\hline Traveled abroad & $\begin{array}{l}0.04 \\
(0.04)\end{array}$ \\
\hline Liberal & $\begin{array}{l}0.21 * * * \\
(0.05)\end{array}$ \\
\hline Education $($ B.A. or higher $=1$ ) & $\begin{array}{l}0.29 * * * \\
(0.04)\end{array}$ \\
\hline \multicolumn{2}{|l|}{ Covariates } \\
\hline Male & $\begin{array}{l}-0.01 \\
(0.04)\end{array}$ \\
\hline Age & $\begin{array}{l}-0.01 * * * \\
(0.00)\end{array}$ \\
\hline Constant & $\begin{array}{l}0.11 \\
(0.11)\end{array}$ \\
\hline F-distribution & $25.86 * * *$ \\
\hline Degrees of freedom & 15 \\
\hline R-square & 0.22 \\
\hline
\end{tabular}


Table 4. Linear regression of attitudes toward immigrants by rural and urban categories in Nebraska, Part A

\begin{tabular}{|c|c|c|c|c|c|c|c|c|}
\hline \multirow[b]{2}{*}{ Variable } & \multicolumn{2}{|c|}{ Open country, farms } & \multicolumn{2}{|l|}{ Towns } & \multicolumn{2}{|c|}{$\begin{array}{l}\text { Small cities, } \\
\text { suburbs, exurbs }\end{array}$} & \multicolumn{2}{|r|}{ Large cities } \\
\hline & Unstd. coef. & Std. coef. & Unstd. coef. & Std. coef. & Unstd. coef. & Std coef. & Unstd. coef. & Std coef. \\
\hline \multicolumn{9}{|l|}{ Threat } \\
\hline Immigrant visibility & $\begin{array}{l}-0.11 \\
(0.10)\end{array}$ & -0.09 & $\begin{array}{l}-0.25 * * \\
(0.09)\end{array}$ & -0.19 & $\begin{array}{l}-0.35 * * * \\
(0.09)\end{array}$ & -0.27 & $\begin{array}{l}-0.18 * * * \\
(0.05)\end{array}$ & -0.12 \\
\hline Perceived increase & $\begin{array}{l}-0.09 \\
(0.11)\end{array}$ & -0.06 & $\begin{array}{l}-0.24 * * * \\
(0.08)\end{array}$ & -0.18 & $\begin{array}{l}-0.02 \\
(0.10)\end{array}$ & -0.01 & $\begin{array}{l}-0.16 \dagger \\
(0.08)\end{array}$ & -0.08 \\
\hline Proportion Latino & $\begin{array}{l}-0.01 \\
(0.15)\end{array}$ & 0.00 & $\begin{array}{l}0.02 \\
(0.08)\end{array}$ & 0.01 & $\begin{array}{l}0.00 \\
(0.09)\end{array}$ & 0.00 & $\begin{array}{l}-0.03 \\
(0.05)\end{array}$ & -0.02 \\
\hline Community safety (unsafe $=1$ ) & $\begin{array}{l}-0.12 \\
(0.10)\end{array}$ & -0.09 & $\begin{array}{l}-0.08 \\
(0.08)\end{array}$ & -0.06 & $\begin{array}{l}-0.17^{*} \\
(0.08)\end{array}$ & -0.11 & $\begin{array}{l}-0.18^{* *} \\
(0.06)\end{array}$ & -0.12 \\
\hline Employment & $\begin{array}{l}-0.07 \\
(0.17)\end{array}$ & -0.03 & $\begin{array}{l}0.00 \\
(0.10)\end{array}$ & 0.00 & $\begin{array}{l}0.08 \\
(0.09)\end{array}$ & 0.05 & $\begin{array}{l}-0.06 \\
(0.08)\end{array}$ & -0.03 \\
\hline \multicolumn{9}{|l|}{ Contact } \\
\hline Interaction & $\begin{array}{l}0.15 \\
(0.10)\end{array}$ & 0.12 & $\begin{array}{l}0.20^{*} \\
(0.08)\end{array}$ & 0.15 & $\begin{array}{l}0.20^{*} \\
(0.09)\end{array}$ & 0.16 & $\begin{array}{l}0.19 * * * \\
(0.06)\end{array}$ & 0.13 \\
\hline Close relationships & $\begin{array}{l}0.22 \\
(0.13)\end{array}$ & 0.13 & $\begin{array}{l}0.44 * * * \\
(0.10)\end{array}$ & 0.26 & $\begin{array}{l}0.14 \\
(0.11)\end{array}$ & 0.10 & $\begin{array}{l}0.20 * * * \\
(0.06)\end{array}$ & 0.14 \\
\hline \multicolumn{9}{|l|}{ Cosmopolitan outlook } \\
\hline Traveled abroad & $\begin{array}{l}0.00 \\
(0.11)\end{array}$ & 0.00 & $\begin{array}{l}0.22 * * * \\
(0.07)\end{array}$ & 0.17 & $\begin{array}{l}0.00 \\
(0.08)\end{array}$ & 0.00 & $\begin{array}{l}-0.01 \\
(0.06)\end{array}$ & -0.01 \\
\hline Liberal & $\begin{array}{l}0.11 \\
(0.16)\end{array}$ & 0.06 & $\begin{array}{l}0.07 \\
(0.09)\end{array}$ & 0.04 & $\begin{array}{l}0.12 \\
(0.13)\end{array}$ & 0.07 & $\begin{array}{l}0.26 * * * \\
(0.07)\end{array}$ & 0.16 \\
\hline Education $($ B.A. or higher $=1$ ) & $\begin{array}{l}0.02 \\
(0.11)\end{array}$ & 0.01 & $\begin{array}{l}0.30 * * * \\
(0.07)\end{array}$ & 0.19 & $\begin{array}{l}0.25 * * \\
(0.09)\end{array}$ & 0.18 & $\begin{array}{l}0.37 * * * \\
(0.05)\end{array}$ & 0.28 \\
\hline \multicolumn{9}{|l|}{ Covariates } \\
\hline Male & $\begin{array}{l}-0.11 \\
(0.10)\end{array}$ & -0.09 & $\begin{array}{l}0.02 \\
(0.07)\end{array}$ & 0.01 & $\begin{array}{l}-0.05 \\
(0.08)\end{array}$ & -0.04 & $\begin{array}{l}0.01 \\
(0.05)\end{array}$ & 0.00 \\
\hline Age & $\begin{array}{l}0.00 \\
(0.00)\end{array}$ & -0.07 & $\begin{array}{l}-0.01 * * \\
(0.00)\end{array}$ & -0.19 & $\begin{array}{l}0.00 \\
(0.00)\end{array}$ & -0.11 & $\begin{array}{l}-0.01 * * * \\
(0.00)\end{array}$ & -0.14 \\
\hline Constant & $\begin{array}{l}0.13 \\
(0.38)\end{array}$ & & $\begin{array}{l}0.22 \\
(0.19)\end{array}$ & & $\begin{array}{l}0.12 \\
(0.17)\end{array}$ & & $\begin{array}{l}0.41^{* *} \\
(0.15)\end{array}$ & \\
\hline N (weighted) & 213 & & 357 & & 300 & & 696 & \\
\hline F-distribution & 1.27 & & $12.98 * * *$ & & $5.35 * * *$ & & $13.26 * * *$ & \\
\hline Degrees of freedom & 15 & & 15 & & 15 & & 15 & \\
\hline R-square & 0.07 & & 0.28 & & 0.19 & & 0.22 & \\
\hline
\end{tabular}

$\dagger<0.10, * \mathrm{p}<0.05 ; * * \mathrm{p}<0.01 ; * * * \mathrm{p}<0.001$; Weighted sample size $=1566$; Robust standard errors in parenthesis

The overall effects of these coefficients for the three hypotheses will be represented and discussed using the predicted averages in Fig. 1 and 2. Figure 1 displays the predicted averages of the presence and absence of the effects of threat, contact and a cosmopolitan outlook on attitudes toward immigrants, with all other variables held at their mean for each of the models. Using the predicted averages allows for the estimation of changes in attitudes given the effects of changes in characteristics for a particular hypothesis. Figure 1 displays the predicted averages for each rural-urban category when all variables are held at their mean and when controlling only for the variables of each hypothesis (threat, contact and cosmopolitanism) separately. Living in open country or on farms is not included in this analysis, because the effects of all the variables in the model are not statistically significant.

For example, in the case of town dwellers, if everyone living in towns were to perceive immigrants as a threat, those variables representing perceived threat, (i.e., the statistically significant variables of the model including immigrant visibility and perceived increase of the number of immigrants) are set equal to one and all other variables are held at their mean, the attitude toward immigration would decline for this population by 0.21 , from -0.03 to -0.24 on the immigration attitudes scale. If on the other hand, every town dweller were to not perceive immigrants as a threat, with these variables set to zero and all others held at their means, the attitude toward immigrants would increase for these respondents to 0.28 , from -0.03 to 0.25 . In the case of the contact hypothesis, attitudes toward immigrants would increase to 0.42 with contact and decrease to -0.22 without contact. Similarly, for the case of cosmopolitanism, the attitudes toward immigrants would increase to 0.30 with a cosmopolitan outlook and decrease to -0.23 without. Thus, for those respondents living in towns, the magnitude of the positive effect of contact with immigrants is greater than all other effects and both the individual effects of contact and a cosmopolitan outlook on attitudes toward immigrants are greater than the negative effect of perceiving immigrants to be a threat. 


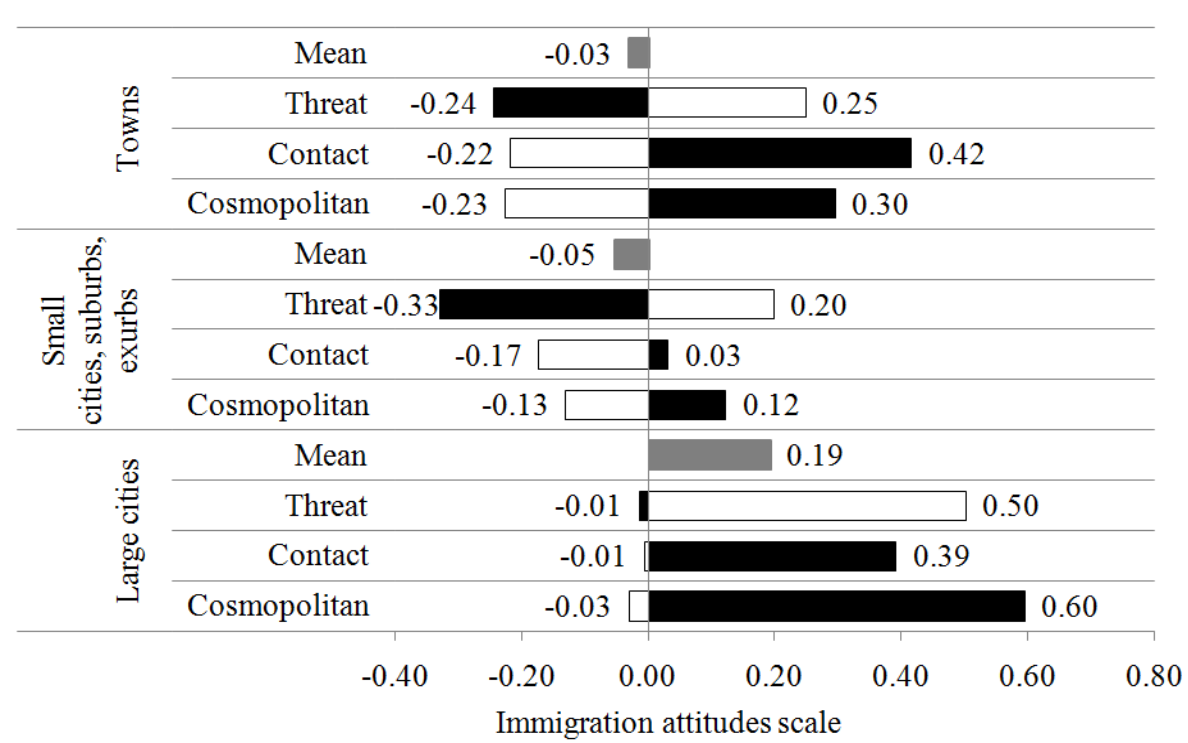

Mean $\quad \square$ Predicted average when $\mathrm{x}=0$

- Predicted average when $\mathrm{x}=1$

Fig. 1. Differences in predicted averages of attitudes toward immigrants on variables representing threat, contact and a cosmopolitan outlook by rural and urban categories in Nebraska; Differences in predicted averages from the mean for the presence or absence of each hypothesis are estimated by assigning a one or zero, respectively, to the related statistically significant variables

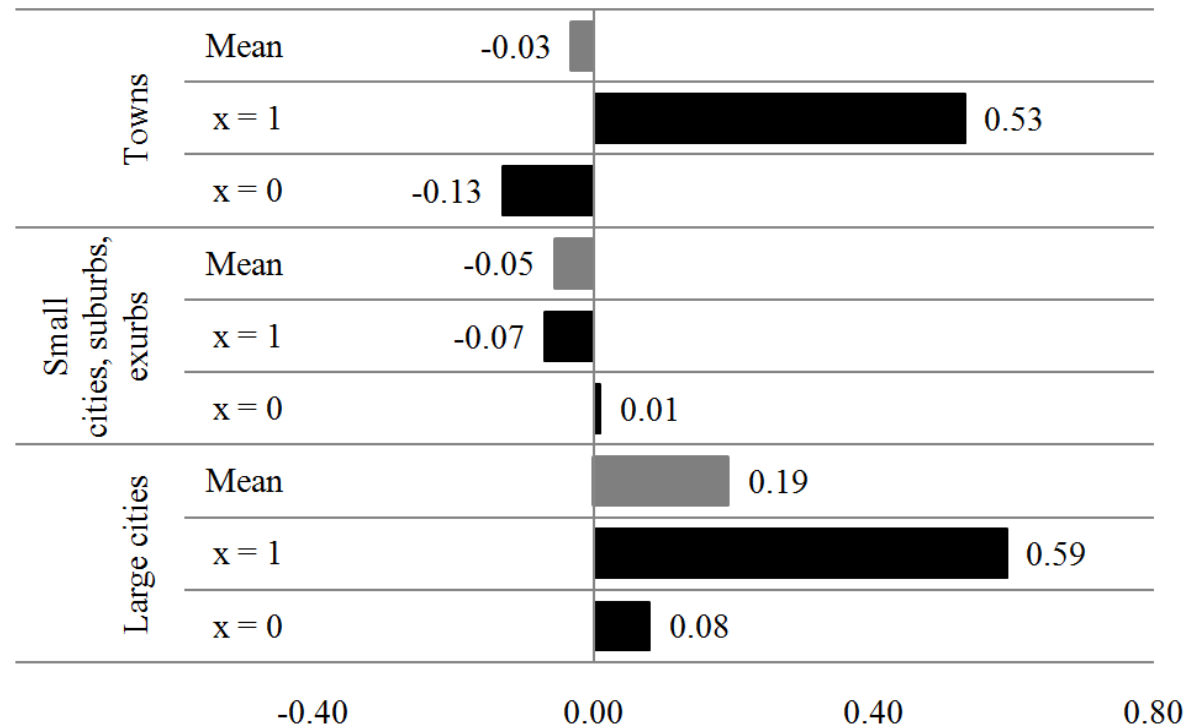

Mean $\quad$ Predicted average

Fig. 2. Differences in combined predicted averages of attitudes toward immigrants on variables representing threat, contact and a cosmopolitan outlook by rural and urban categories in Nebraska; Differences in combined predicted averages from the mean for the presence or absence of each hypothesis are estimated by assigning a one or zero, respectively, to the related statistically significant variables

In the case of those Nebraskans living in small cities or suburbs, the results are significantly different. The negative effect of threat on attitudes is substantially greater than either of the effects from contact or a cosmopolitan outlook. An analysis of the combined effects of contact and cosmopolitanism (not shown here) finds that the magnitude of the negative effect of the threat variables of attitudes toward immigrants $(-0.33)$ is greater than that of the combined positive effects of contact and a cosmopolitan outlook (0.21). In addition, 
the absence of threat has a larger positive effect on attitudes than the positive effect of contact or a cosmopolitan outlook. Furthermore, the effects of contact and a cosmopolitan outlook cannot be underestimated, as the absence of either also has substantial negative effects on attitudes.

For those Nebraskans living in large cities, the positive effects of contact and a cosmopolitan outlook clearly dominate the negative effect of threat. The predicted averages for the presence of threat results in a slightly negative value $(-0.01)$ on the attitudes scale while the presence of contact and a cosmopolitan outlook is substantially positive $(0.39$ and 0.60 respectively). In addition, even with the absence of contact or a cosmopolitan outlook, the predicted averages are only slightly negative.

The effects of the three hypotheses are combined in Fig. 2 to show their overall net effect on attitudes. For each of the rural-urban categories, the statistically significant variables that represent the three hypotheses are first assigned a one to determine the separate net effects of perceived threat, contact with immigrants and a cosmopolitan outlook. For those living in towns and large cities, the net effect of threat, contact and cosmopolitanism is strongly positive with predicted averages of the attitudes scale over 0.50 . On the other hand, for small cities or suburbs, the net effect is slightly negative (-0.05). Thus, the positive effects of contact and cosmopolitanism greatly outweigh the negative effects of threat for those living in towns and urban areas, whereas the opposite is marginally true for those living in small cities or suburbs. These rural-urban categories are then assigned a zero to determine the net effect of the absence of threat, contact and a cosmopolitan outlook. The results show the effects are small relative to the positive effects of the presence of these characteristics: For those living in large or small cities or suburbs, the net effect is positive (0.08 and 0.01 , respectively) and negative for those living in towns $(-0.13)$.

\section{Discussion}

This study examines attitudes toward immigrants in Nebraska, which until recently has been insulated from the high influx of immigrants common among immigrant-receiving states, such as California, Texas, or New York. Nebraska, like many other states in the Great Plains, Midwest and the South, is currently undergoing a rapidly growing immigrant population. We sought to determine the variation of factors influencing the formation of attitudes toward immigrants within and between the urban and rural areas of Nebraska by examining the theoretical suppositions and demographic correlates of these attitudes.
We found the effect of contact to be strongest among those living in towns and the effect of a cosmopolitan outlook to be strongest among those living in large cities. Alternatively stated, those Nebraskans living in small cities or suburbs are the least swayed in a positive direction by contact with immigrants or a cosmopolitan outlook as compared to those living in towns or large cities. This may be due to the size of the communities and context of contact. In small towns, contact may involve repeated and a more meaningful interaction with the same individuals over a long period of time, thus enabling a development of stronger relationships between the residents and newcomers. For small cities and suburbs, on the other hand, the lack of experience with immigration coupled with a greater social distance between residents and immigrants because of the population size and residential patterns may limit the development of close relationships and contribute to greater mistrust of these newcomers by the residents. The positive experience of contact found in the larger cities may be influenced by the cosmopolitan outlook of its residents that contributes to more accepting attitudes toward newcomers and a greater willingness to interact with immigrants.

We also found that the effects of perceived threat, contact, or a cosmopolitan outlook have no influence on attitudes toward immigrants for those living in the least populated areas of the state-those living in open country or on farms. In addition, we also found that the effect of contact and a cosmopolitan outlook on attitudes overpowers the negative effects of perceived threat in the towns and large cities. For small cities, this is not the case, but at a minimum the negative effect is somewhat neutralized.

Finally, traveling abroad was found to be positive and significant only for those respondents living in towns and as a result, a cosmopolitan outlook had a strong positive effect on attitudes toward immigrants, unlike other regions outside of the large cities. There appears to be something unique about the context of living in a small community that contributes to such a differential effect on attitudes in these regions. In addition, in a state where immigration is a relatively new phenomenon and almost entirely motivated by economic necessity, especially in small towns experiencing economic and population decline, the residents may have a more practical appreciation of the value of immigration.

Our results are consistent with the authors earlier findings (Ceballos and Yakushko, 2014) and other studies showing that perceived threat contributes to an increase in unfavorable attitudes toward immigrants and support for restrictive policies on immigration, whereas contact with immigrants and a cosmopolitan outlook decreases such attitudes and support for such policies (Chandler and Tsai, 2001; Espenshade and Hempstead, 
1996; Haubert and Fussell, 2006; McLaren, 2003; Quillian, 1995; Ward and Masgoret, 2006). However, we find that this pattern varies significantly by place of residence. Those living in the least populated areas of the state -in open country or on farms-did not experience the hypothesized effects of threat, contact, or cosmopolitanism on their attitudes toward immigrants. This study builds upon past work that examines the effects of these theoretical suppositions on attitudes toward immigrants by examining the heterogeneity of attitudes and those factors which influence them within a rural and urban context. Current sociopolitical events in the state further support our findings and help to explain the rise of antiimmigrant sentiment in particular regions of the state, specifically in small cities, such as the city of Fremont (Fitzsimmons, 2014; Hovey, 2010).

Our findings may be significant in suggesting how attitudes toward immigrants are formed and can be changed. Reducing feelings of threat and increasing social contact contribute to more positive attitudes toward immigrants. In addition, encouraging a more cosmopolitan outlook through various means such as increased educational and foreign exchange opportunities may also be helpful. However the effects are strongest for those living in towns and large cities.

Although our results were similar to the findings of other studies on rural-urban differences on attitudes toward immigrants, several notable differences were found. In contrast to previous studies, gender and the proportion of Latinos living in these areas did not play a significant role in attitudes toward immigrants (Chandler and Tsai, 2001; Leong and Ward, 2006; Vega, 2006; Ward and Masgoret, 2006). Perhaps the role of gender in the formulation of attitudes may differ by region. In the case of the Latino population, it may be that a more targeted analysis is required of specific regions within the state.

There are several limitations of this study that must be noted. First, the survey does not distinguish between immigration in general and recent immigrants in particular. It would be important to examine whether negative attitudes toward immigrants are similar when considering all immigrant groups or particular groups, such as Mexicans (the largest immigrant group in Nebraska and in the United States as a whole). Attitudes may vary toward different immigrant groups and have different motivations, which may not necessarily be xenophobic. For example, racialized anti-Latino sentiments may become conflated with an antiimmigrant attitude. In addition it would be necessary to separate out the effect of negative attitudes that are directly focused on undocumented immigration. It is not clear that the respondents' attitudes are of immigration in general, undocumented immigration in particular, or both. Finally, the relative effects of the different hypotheses may be influenced by omitted variables. Further analysis would be enhanced with the inclusion of additional measures of threat, contact and a cosmopolitan outlook.

\section{Conclusion}

This study suggests that while attitudes toward immigrants in Nebraska across various rural and urban locations are primarily negative, the perceptions of threat, experiences of contact and a cosmopolitan outlook play a significant role in shaping attitudes toward immigrants, in both a more favorable and unfavorable direction. Furthermore, the effect of these perceptions, interactions and world views vary between and within rural and urban areas. By considering the relative effects of threat, contact and a cosmopolitan outlook within the rural and urban context, we can better understand how attitudes toward immigrants develop and change in the Great Plains region experiencing a demographic transformation due to a rapid influx of immigrants. This is particularly relevant for understanding the rise in anti-immigrant sentiment in this region over the past decade. Efforts to understand these complex social realities are not only necessary for the establishment of a greater understanding of xenophobia but also for the improvement of policies and practices related to immigrants and their integration into society.

\section{Acknowledgment}

The researchers express thanks to the Bureau of Sociological Research of the University of NebraskaLincoln for including our questions on immigration attitudes in the 2006 Nebraska Annual Social Indicators Survey.

\section{Author's Contributions}

Miguel Ceballos: Conceptualization of the study, development of the instrument, analysis of the data, interpretation and report of the results.

Oksana Yakushko: Conceptualization of the study, development of the instrument, interpretation and report of the results.

Courtney Lyons: Conceptualization of the study, and interpretation and report of the results.

\section{Funding Information}

This study received funding from the Bureau of Sociological Research of the University of Nebraska- 
Lincoln to include our survey questions in the 2006 Nebraska Annual Social Indicators Survey.

\section{Ethics}

Because of the anonymous nature of this research, no ethical concerns are expected following the release of this article.

\section{References}

Allport, G.W., 1954. The Nature of Prejudice. 1st Edn., Addison-Wesley, Cambridge, Mass, pp: 537.

Alvarado, E., 2009. Attitudes toward immigrants and multiculturalism in contemporary America: The role of foreign language fluency. Sociat. Today.

Bean, C., 1995. Determinants of attitudes toward questions of border maintenance in Australia. People Places, 3: 32-40.

Berg, J.A., 2009. Core networks and whites' attitudes toward immigrants and immigration policy. Public Opin. Q., 73: 7-31. DOI: 10.1093/poq/nfp011

Betts, K., 1988. Ideology and Immigration: Australia 1976 to 1987.1 st Edn., Melbourne University Press, Carlton, ISBN-10: 0522843514, pp: 234.

Bodvarsson, O. and H. Van den Berg, 2003. The impact of immigration on a local economy: The case of Dawson county, Nebraska. Great Plains Res., 13: 291-309.

Boehnke, K., J. Hagan and G. Hefler, 1998. On the development of xenophobia in Germany: The adolescent years. J. Soc. Issues, 54: 585-602. DOI: 10.1111/j.1540-4560.1998.tb01237.x

Bruce-Briggs, B., 1979. The New Class? 1st Edn., Transaction Books, ISBN-10: 1412829550, pp: 229.

BSR, 2006a. Nebraska annual social indicators survey 2006. Bureau of Sociological Research, University of Nebraska-Lincoln.

BSR, 2006b. Nebraska Annual social indicators survey 2006: Methodology report-designs, procedures, instruments and forms. University of NebraskaLincoln Department of Sociology, Lincoln, Nebraska.

Capps, R., R.M. Castañeda, A. Chaudry and R. Santos, 2007. Paying the price: The impact of immigration raids on America's children. The Urban Institute.

Ceballos, M. and O. Yakushko, 2014. Attitudes toward immigrants in Nebraska. Great Plains Res., 24: 181195. DOI: $10.1353 /$ gpr.2014.0042

Chandler, C.R. and Y.M. Tsai, 2001. Social factors influencing immigration attitudes: An analysis of data from the general social survey. Soc. Sci. J., 38: 144-188. DOI: 10.1016/S0362-3319(01)00106-9

Citrin, J. and J. Sides, 2007. Immigration and the imagined community in Europe and the United States. Polit. Stud., 56: 33-56.

DOI: $10.1111 / \mathrm{j} .1467-9248.2007 .00716 . x$
Cromartie, J. and S. Bucholtz, 2008. Defining the "rural" in rural America. Economic Research Service: USDA.

Ennis, S.R., M. Rios-Vargas and N.G. Albert, 2011. The Hispanic population: 2010. U.S. Census Bureau, Washington, DC.

ERS, 2004. Rural poverty at a glance. Economic Research Service: USDA. Agriculture Information Bulletin No. 793.

Espenshade, T.J. and K. Hempstead, 1996. Contemporary American attitudes toward U.S. immigration. Int. Migrat. Rev., 30: 535-570. DOI: $10.2307 / 2547393$

Esses, V.M., J.F. Dovidio, K.L. Dion and T.L. Armstrong, 2001. The immigration dilemma: The role of perceived group competition, ethnic prejudice and national identity. J. Soc. Issues, 57: 389-412. DOI: $10.1111 / 0022-4537.00220$

Federico, C. and K. Fennelly, 2008. Rural residence as a determinant of attitudes toward US immigration policy. Int. Migrat., 46: 151-190. DOI: $10.1111 / \mathrm{j} .1468-2435.2008 .00440 . \mathrm{x}$

Fitzsimmons, E.G., 2014. Nebraska City Votes to Keep Rule Aimed at Illegal Immigrants. New York Times.

Gimpel, J.G. and J.C. Lay, 2008. Political socialization and reactions to immigration-related diversity in rural America. Rural Sociol., 73: 180204. DOI: $10.1526 / 003601108784514561$.

Gouveia, L., M.A. Carranza, J. Cogua, V. Zuniga and R. Hernandez-Leon, 2005. The great plains migration: Mexicanos and Latinos in Nebraska. In: New Destinations: Mexican Immigration in the United States, Zuniga, V. and R. Hernandez-Leon (Eds.), Russell Sage Foundation, New York, ISBN-10: 1610445708, pp: 23-49.

Guzmán, B., 2001. The Hispanic population: Census 2000 Brief. United States Census Bureau.

Hainmueller, J. and M.J. Hiscox, 2007. Educated preferences: Explaining attitudes toward immigration in Europe. Int. Organiz., 61: 399-442. DOI: $10.1017 / \mathrm{S} 0020818307070142$

Haubert, J. and E. Fussell, 2006. Explaining proimmigrant sentiment in the US: Social class, cosmopolitanism and perceptions of immigrants. Int. Migrat. Rev., 40: 489-507. DOI: $10.1111 /$ j.1747-7379.2006.00033.x

Hood, M.V. and I.L. Morris, 1998. Give us your tired, your poor, ... But make sure they have a green card: the effects of documented and undocumented migrant context on Anglo opinion toward immigration. Polit. Behav., 20: 1-15. DOI: 10.1023/A:1024839032001

Hovey, A., 2010. Fremont approves illegal-immigration measure. Lincoln J. Star.

Hovey, J.D., R.S. Rojas, C. Kain and C. Magana, 2000. Proposition 187 reexamined: Attitudes toward immigration among California voters. Curr. Psychol., 19: 159-174. DOI: 10.1007/s12144-000-1013-9 
Jenkins, N., 2010. Lawmaker plans Arizona-style immigrant bill for Nebraska. Lincoln J. Star.

Jones, M. and E. Larson, 2003. Length of normal labor in women of Hispanic origin. J. Midwifery Womens Health, 48: 2-9.

DOI: 10.1016/S1526-9523(02)00367-7

Leong, C.H. and C. Ward, 2006. Cultural values and attitudes toward immigrants and multiculturalism: The case of the Eurobarometer survey on racism and xenophobia. Int. J. Intercultural Relat., 30: 799-810. DOI: 10.1016/j.ijintrel.2006.07.001

Mayda, A.M., 2006. Who is against immigration? A cross-country investigation of individual attitudes toward immigrants. Rev. Econom. Stat. 88: 510-530.

McLaren, L.M., 2003. Anti-immigrant prejudice in Europe: Contact, threat perception and preferences for the exclusion of migrants. Soc. Forces, 81: 909936. DOI: $10.1353 /$ sof.2003.0038

Neal, M. and S.A. Bohon, 2003. The dixie diaspora: Attitudes toward immigrants in Georgia. Sociol. Spectrum, 23: 181-212. DOI: $10.1080 / 02732170309215$

Ochoa, G.L., 2000. Mexican Americans' attitudes toward and interactions with Mexican immigrants: A qualitative analysis of conflict and cooperation. Soc. Sci. Q., 81: 84-105.

OLLAS, 2010. Nebraska's foreign-born and hispanic/latino population: Demographics trends 1990-2008. Demographic and Socio-Economic Trends Data Series. University of Nebraska at Omaha, Omaha.

Pantoja, A., 2006. Against the tide? Core American values and attitudes toward US immigration policy in the mid-1990s. J. Ethnic Migrat. Stud., 32: 515531. DOI: 10.1080/13691830600555111

Quillian, L., 1995. Prejudice as a response to perceived group threat: Population composition and antiimmigrant and racial prejudice in Europe. Am. Sociol. Rev., 60: 586-611. DOI: 10.2307/2096296

Scheunpflug, A., 1997. Cross-cultural encounters as a way of overcoming xenophobia. Int. Educ. Rev., 43: 109-116. DOI: 10.1023/A:1002914732451

Scheve, K.F. and M.J. Slaughter, 2001. Labor market competition and individual preferences over immigration policy. Rev. Econom. Stat., 83: 133145. DOI: $10.1162 / 003465301750160108$

Sherif, M., O.J. Harvey, B.J. White, W.R. Hood and C.W. Sherif, 1961. Intergroup conflict and cooperation: The robbers cave experiment. University of Oklahoma.

Sorensen, M. and H. Krahn, 1996. Attitudes toward immigrants: A test of two theories. Alberta J. Educ. Res., 42: 3-18.
Stephan, W.G. and C.W. Stephan, 1996. Intergroup Relations. 1st Edn., Westview Press, Madison, ISBN-10: 0813330084, pp: 223.

Stephan, W.G., O. Ybarra and G. Bachman, 1999. Prejudice toward immigrants. J. Applied Soc. Psychol., 29: 2221-2237. DOI: $10.1111 /$ j.1559-1816.1999.tb00107.x

Streeck-Fischer, A., 1999. Xenophobia and Violence by Adolescent Skinheads. In: Trauma and Adolescence, Sugar, M. (Ed.), International Universities Press Inc., Madison, ISBN-10: 0823666263, pp: 251-269.

Thornton, M.C. and Y. Mizuno, 1999. Economic wellbeing and black adult feelings toward immigrants and whites, 1984. J. Black Stud., 30: 15-44. DOI: 10.1177/002193479903000102

USCB, 2005. Statistical abstracts of the United States: 2004-2005. U.S. Census Bureau.

USCB, 2013. Annual estimates of the resident population. Nebraska.

USCB, 2014. The size, place of birth, and geographic distribution of the foreign-born population in the United States: 1960 to 2010. U.S. Census Bureau.

Vega, A., 2006. “Americanizing?" Attitudes and perceptions of U.S. Latinos. Harvard J. Hispanic Policy, 18: 39-57.

Vogt, R.J., R.L. Cantrell, M.A. Carranza, B.B. Johnson and A.J. Tomkins, 2006. Perceptions of Latino American immigration among rural Nebraskans. University of Nebraska, Lincoln, Nebraska.

Ward, C. and A.M. Masgoret, 2006. An integrative model of attitudes toward immigrants. Int. J. Intercultural Relat., 30: 671-682. DOI: 10.1016/j.ijintrel.2006.06.002

Wilson, T.C., 2001. Americans' views on immigration policy: Testing the role of threatened group interests. Sociol. Perspectives, 44: 485-501. DOI: $10.2307 / 1389655$

Yakushko, O., 2009. Xenophobia: Understanding the roots and consequences of negative attitudes toward immigrants. Counsel. Psychol., 37: 36-66. DOI: $10.1177 / 0011000008316034$ 